ISSN : $2450-766 X$

\title{
PREDIKSI POLA PENYEBARAN MERKURI (Hg) DI UDARA PADA KONDISI STEADY STATE DI KAWASAN PERTAMBANGAN EMAS POBOYA, KOTA PALU MENGGUNAKAN METODE BEDA HINGGA
}

\author{
R. Nirmalasari' , A. I. Jaya ${ }^{2}$, R. Ratianingsih ${ }^{3}$ \\ 1,2,3Program Studi Matematika Jurusan Matematika FMIPA Universitas Tadulako \\ Jalan Soekarno-Hatta Km. 09 Tondo, Palu 94118, Indonesia \\ 11ririn.nirmalasari@gmail.com, 2,3ratianingsih@yahoo.com
}

\begin{abstract}
The increasing number of gold miners in Poboya village Palu city, causes the environmental damage caused by the mercury substance. In the amalgamation process, the mercury is used to bind the gold. Based on the dangerous of mercury, it is very important to study the mercury spread pattern nearby Poboya and the surrounding. The mercury spread is considered as the advection-diffusion modelled in air media. Assuming the model in steady state condition, where the system is not depend on time, we come to a modified advectiondiffusin model $u_{x} \frac{\partial C}{\partial x}=\varepsilon_{y} \frac{\partial^{2} C}{\partial y^{2}}$ that satisfy such initial and boundary condition. The numerical scheme is derived from the model that represents the concentration in the region. Later on, these values is used to draw the mercury spread pattern. The research result shows that the pattern is similar for given value of atmosphere stability parameter. The spread will follow the wind direction. The simulation also shows that the Poboya village and the North Palu district are categorized as highly dangerous region, while the West Palu District being the savest ones with respect to the mercury spread.
\end{abstract}

Keyword : Advection-Diffusion, Finite Difference, Mercury, Steady State

\section{ABSTRAK}

Meningkatnya jumlah penambang emas di kawasan Kelurahan Poboya, Kota Palu menyebabkan terjadinya kerusakan lingkungan akibat zat merkuri yang digunakan untuk mengikat emas dalam proses amalgamasi. Mengingat merkuri dikategorikan sebagai zat berbahaya, penelitian ini bertujuan untuk mengkaji pola penyebaran merkuri di udara pada kawasan tersebut. Pola penyebaran merkuri $(\mathrm{Hg})$ melalui media udara dikaji melalui model modifikasi dari persamaan adveksi-difusi dengan asumsi sistem dalam keadaan steady state (variabel waktu tidak diperhitungkan). Modifikasi model tersebut adalah $\mathrm{u}_{\mathrm{x}} \frac{\partial \mathrm{C}}{\partial \mathrm{x}}=\varepsilon_{\mathrm{y}} \frac{\partial^{2} \mathrm{C}}{\partial \mathrm{y}^{2}}$ yang dilengkapi dengan syarat awal dan syarat batas untuk kondisi kestabilan atmosfer yang berbeda-beda. Skema numerik diperoleh dengan menggunakan metode beda hingga untuk mendapatkan solusi numerik. Solusi tersebut menggambarkan model modifikasi sebaran nilai-nilai konsentrasi merkuri yang akan menggambarkan pola penyebarannya. Hasil simulasi model memperlihatkan pola penyebaran merkuri yang serupa yakni mengikuti arah angin. Simulasi juga memberikan hasil bahwa dampak pencemaran merkuri di udara pertambangan emas Poboya memperlihatkan 
bahwa Kota Palu yang berpotensi sangat besar yaitu Kelurahan Poboya hingga Kecamatan Palu Utara, sedangkan yang paling kecil resiko terkena dampak pencemaran merkuri di udara yaitu wilayah Palu Barat.

Kata Kunci : Adveksi-Difusi, Beda Hingga, Merkuri, Steady State

\section{PENDAHULUAN}

Meningkatnya jumlah penambang emas di lingkungan kelurahan Poboya, Kota Palu menyebabkan terjadinya kerusakan lingkungan akibat zat merkuri yang digunakan untuk mengikat emas dalam proses amalgamasi. Merkuri $(\mathrm{Hg})$ adalah unsur kimia yang berbentuk cair dan mudah menguap serta bersifat toksik bagi tubuh manusia. Dampak pencemaran merkuri tidak hanya dirasakan oleh para pekerja tambang, tetapi juga dapat mempengaruhi ekosistem makhluk hidup lainnya. Merkuri bersifat mengendap pada batuan dan pakaian pekerja tambang, serta dapat mengalir mengikuti aliran sungai maupun air tanah.

Dalam laporan kampanye bebas merkuri IPEN mengenai titik rawan merkuri di Indonesia menyebutkan bahwa konsentrasi merkuri tertinggi di daerah pertambangan emas Poboya terdapat di dua lokasi pusat pengoperasian tromol dengan masing-masing 4.050 dan 5.986 nanogram per meter kubik. Angka tersebut melampaui ambang batas standar WHO yakni 1.000 nanogram per meter kubik (Ismawati, 2013).

Pola penyebaran merkuri $(\mathrm{Hg})$ melalui media udara dapat dikaji berdasarkan pemodelan persamaan matematika yang merepresentasikan proses aliran merkuri. Model yang digunakan merupakan modifikasi dari persamaan adveksi-difusi pada keadaan sistem steady state. Berdasarkan model tersebut dibuat suatu skema numerik dengan metode beda hingga untuk mendapatkan solusi numerik berupa sebaran nilai-nilai konsentrasi merkuri yang akan menggambarkan pola penyebarannya. Metode ini paling banyak digunakan dalam menyelesaikan persamaan differensial karena memiliki bentuk sederhana dan mudah untuk dipahami serta menghasilkan nilai akurasi yang baik. Pada penelitian ini beberapa faktor yang perlu diperhatikan yakni karakteriristik stabilitas atmosfer, faktor-faktor meteorologi dan koefisien difusi yang berasal dari berbagai literatur dan lembaga yang mempunyai data-data tersebut.

\section{METODE PENILITIAN}

Penelitian ini dilakukan sesuai prosedur penelitian sebagai berikut :

1. Tahap awal pada penelitian ini dilakukan studi pustaka untuk mencari referensi yang sesuai dengan subjek penelitian.

2. Identifikasi masalah dilakukan untuk mencari tahu masalah yang ada sehingga dapat ditentukan asumsi penelitian. 
3. Pengambilan data observasi secara langsung ke lokasi penelitian untuk selanjutnya ke berbagai instansi.

4. Data-data yang telah didapat kemudian diolah sesuai dengan kebutuhan model dan metode yang dipilih.

5. Membangun model modifikasi dari persamaan adveksi-difusi.

6. Model tersebut pada langkah 5 , kemudian dibuatkan skema beda hingganya.

7. Agar skema pada langkah 6 konvergen ke persamaan modifikasi adveksi-difusi, maka perlu ditentukan syarat kestabilan dan konsistensi skema tersebut.

8. Skema yang telah dijamin kekonvergenannya, selanjutnya diimplementasikan pada daerah observasi penelitian. Pada tahap ini ditentukan jarak antar titik perhitungan terhadap arah $\mathrm{x}$ dan y yang memenuhi syarat kekonvergenan.

9. Nilai awal dan syarat batas ditentukan berdasarkan data-data yang ada dan geometri daerah observasi.

10. Setelah semua data terkumpul dan nilai awal serta syarat batas ditentukan, maka dibuat suatu program aplikasi menggunakan software Matlab versi 7.7 R2008b untuk mensimulasikan pola penyebaran polutan merkuri di kawasan pertambangan emas Poboya.

11. Hasil simulasi kemudian dianalisis untuk mendapatkan jangkauan wilayah yang terkena dampak penyebarannya.

Tahap akhir dalam proses penelitian yaitu menarik kesimpulan dari hasil simulasi pola penyebaran merkuri di udara dan penentuan tingkat-tingkat kerawanan daerah observasi berdasarkan tingkat kandungan merkurinya.

\section{HASIL DAN PEMBAHASAN}

\subsection{Model Modifikasi Persamaan Adveksi-Difusi}

Proses adveksi-difusi dipengaruhi oleh faktor-faktor metereologi seperti arah angin dan kecepatan angin. Proses ini direpresentasikan melalui persamaan adveksi-difusi atau persamaan transportasi polutan sebagai berikut (Mosey, 2011):

$$
\frac{\partial \mathrm{C}}{\partial \mathrm{t}}=-U \nabla \mathrm{C}+\varepsilon \nabla^{2} \mathrm{C}
$$

Adveksi Difusi

dimana

$\mathrm{C}=$ konsentrasi $\mathrm{Hg}$ di udara (nanogram $/ \mathrm{m}^{3}$ )

$\mathrm{U}=$ kecepatan angin rata-rata $(\mathrm{m} / \mathrm{s})$

$\varepsilon=$ konstanta difusi

Persamaan (1) dapat dijabarkan dalam bentuk persamaan differensial parsial (PDP) 3dimensi orde-2 dalam arah $\mathrm{x}, \mathrm{y}$ dan $\mathrm{z}$ di bawah ini: 
$\frac{\partial C}{\partial t}=-\left(u_{x} \frac{\partial C}{\partial x}+u_{y} \frac{\partial C}{\partial y}+u_{z} \frac{\partial C}{\partial z}\right)+\left(\varepsilon_{x} \frac{\partial^{2} C}{\partial x^{2}}+\varepsilon_{y} \frac{\partial^{2} C}{\partial y^{2}}+\varepsilon_{z} \frac{\partial^{2} C}{\partial z^{2}}\right)$

Persamaan (2) dimodifikasi berdasarkan asumsi-asumsi berikut (Colls, 2002) :

1. Sumber emisi menghasilkan material secara kontinyu.

2. Karakteristik arah angin adalah homogen secara vertikal atau horizontal dan kecepatan rata-ratanya tidak berubah.

3. Transformasi kimia dan fisika di atmosfer tidak diperhitungkan

4. Sistem dalam keadaan tunak (steady state) yaitu kondisi sewaktu sifat-sifat suatu sistem tak berubah dengan berjalannya waktu atau dengan kata lain konstan (http://id.wikipedia.org/wiki/Keadaan_tunak).

5. Permukaan domain penelitian dianggap datar.

6. Sumbu vertikal domain penelitian sejajar dengan arah angin. Pada penelitian ini arah angin dominan menuju ke arah utara.

Hasil modifikasi model persamaan adveksi-difusi, dinyatakan dalam bentuk persamaan berikut.

$u_{x} \frac{\partial C}{\partial x}=\varepsilon_{y} \frac{\partial^{2} C}{\partial y^{2}}$

dimana $\varepsilon_{y}=\frac{u_{x} \cdot \sigma_{y}^{2}}{2 x}$. Persamaan ini yang digunakan untuk mengetahui pola penyebaran merkuri di udara pada kawasan pertambangan emas Poboya, Kota Palu.

\subsection{Skema Beda Hingga untuk Model Modifikasi Persamaan Adveksi-Difusi}

Salah satu metode yang sering digunakan untuk mencari solusi numerik dari suatu permasalahan adalah metode beda hingga. Konsep utama metode ini didapat melalui ekspansi Taylor yang pendekatannya melalui diskretisasi (membagi domain menjadi grid-grid) daerah domain ke dalam suatu daerah 2-dimensi dengan lebar grid tertentu dan diberikan nilai awal serta syarat batas (boundary condition).

Berikut uraian pembentukan skema eksplisit beda hingga untuk persamaan (3).

$C(y, x)=C_{j}^{m}$

dimana $C$ merepresentasikan konsentrasi merkuri pada titik $(y, x)$. Skema beda maju untuk mendiskritkan turunan pertama terhadap $\mathrm{x}$ adalah:

$\frac{\partial C(y, x)}{\partial x}=\frac{C_{j}^{m+1}-C_{j}^{m}}{\Delta x}$.

Sedangkan skema beda pusat untuk mendiskritkan turunan kedua terhadap y adalah:

$\frac{\partial^{2} C(y, x)}{\partial y^{2}}=\frac{C_{j+1}^{m}-2 C_{j}^{m}+C_{j-1}^{m}}{(\Delta y)^{2}}$

Substitusi persamaan (5) dan (6) ke dalam persamaan (3) sehingga skema beda hingga pola penyebaran merkuri dirumuskan sebagai berikut. 
$C_{j}^{m+1}=\alpha C_{j+1}^{m}+(1-2 \alpha) C_{j}^{m}+\alpha C_{j-1}^{m}$

dimana $\alpha=\frac{\varepsilon_{y} \Delta x}{u_{x}(\Delta y)^{2}}$.

\subsection{Kekonvergenan Skema Beda Hingga untuk Modifikasi Persamaan Adveksi-Difusi}

Skema beda hingga yang diperoleh pada persamaan (7) akan diuji kekonvergenannya, untuk memberikan jaminan bahwa solusi hampiran yang diberikannya akan konvergen ke solusi analitik persamaan (3). Pengujian dilakukan melalui pencarian syarat kestabilan dan kekonsistenan skema beda hingga.

Persamaan beda hingga dikatakan stabil jika menghasilkan solusi $\mathrm{T}_{i}^{\mathrm{m}}$ yang berhingga. Pada penelitian ini kestabilan skema beda hingga diuji melalui analisis kestabilan von Neumann. Metode von Neumann mendefinisikan bahwa suatu skema beda hingga dikatakan stabil jika dan hanya jika memenuhi syarat berikut (Prasetya, 2012):

$|\rho| \leq 1$

Untuk mendapatkan nilai a yang menjamin skema beda hingga pada persamaan (7) stabil, maka syarat yang harus dipenuhi adalah:

$0 \leq 2 \alpha\left(\sin ^{2}\left(\frac{a \Delta y}{2}\right)\right) \leq 1$

Nilai $\sin \left(\frac{a \Delta y}{2}\right)$ terletak di antara -1 sampai 1 , sehingga $2 \alpha \leq 1$. Jadi, skema stabil jika nilai $\alpha=\frac{\varepsilon_{y} \Delta x}{u_{x}(\Delta y)^{2}} \leq \frac{1}{2}$.

Persamaan beda dikatakan konsisten terhadap PDP yang membangunnya apabila selisih antara persamaan beda dengan PDPnya menuju nol jika lebar grid menuju nol yaitu $\Delta \mathrm{x}$ $\rightarrow 0, \Delta t \rightarrow 0$. Melalui ekspansi Taylor di sekitar $C_{j}^{m+1}$ dan $C_{j \pm 1}^{m}$ diperoleh dua hampiran berikut: $\mathrm{C}_{\mathrm{j}}^{\mathrm{m}+1}=\mathrm{C}_{\mathrm{j}}^{\mathrm{m}}+\left.\Delta \mathrm{x} \mathrm{C}_{\mathrm{x}}\right|_{\mathrm{j}} ^{\mathrm{m}}+\left.\frac{1}{2 !} \Delta \mathrm{x}^{2} \mathrm{C}_{\mathrm{xx}}\right|_{\mathrm{j}} ^{\mathrm{m}}+\mathrm{O}\left(\Delta \mathrm{x}^{3}\right)+\left.\frac{1}{4 !} \Delta \mathrm{x}^{4} \mathrm{C}_{4 \mathrm{x}}\right|_{\mathrm{j}} ^{\mathrm{m}}+\cdots$

$\mathrm{C}_{\mathrm{j} \pm 1}^{\mathrm{m}}=\mathrm{C}_{\mathrm{j}}^{\mathrm{m}} \pm\left.\Delta \mathrm{y} \mathrm{C}_{\mathrm{y}}\right|_{j} ^{\mathrm{m}}+\left.\frac{1}{2 !} \Delta \mathrm{y}^{2} \mathrm{C}_{\mathrm{yy}}\right|_{\mathrm{j}} ^{\mathrm{m}} \pm \mathrm{O}\left(\Delta \mathrm{y}^{3}\right)+\left.\frac{1}{4 !} \Delta \mathrm{y}^{4} \mathrm{C}_{4 \mathrm{y}}\right|_{\mathrm{j}} ^{\mathrm{m}}+\cdots$

Substitusi kedua persamaan di atas ke dalam persamaan (7) menghasilkan persamaan berikut:

$\left.\left(C_{x}-\left(\frac{\varepsilon_{y}}{u_{x}}\right) C_{y y}\right)\right|_{j} ^{m}+\left.\frac{1}{2} \frac{\varepsilon_{y}}{u_{x}}\left(\Delta x \quad \frac{\varepsilon_{y}}{u_{x}} C_{4 y}-\frac{1}{6} \Delta y^{2} C_{4 y}\right)\right|_{j} ^{m}+\cdots=0$

Suku pertama pada persamaan (12) adalah model modifikasi persamaan Adveksi-

Difusi. Suku kedua dan seterusnya pada persamaan (12) adalah suku tambahan yang disebut truncation term sebagai berikut:

truncation term $=\left.\frac{1}{2} \frac{\varepsilon_{y}}{u_{x}}\left(\Delta x \quad \frac{\varepsilon_{y}}{u_{x}} C_{4 y}-\frac{1}{6} \Delta y^{2} C_{4 y}\right)\right|_{j} ^{m}$ 
Persamaan (13) memperlihatkan truncation term akan bernilai nol jika $\alpha=\frac{\varepsilon_{y} \Delta x}{u_{x}(\Delta y)^{2}}=\frac{1}{6}$. Pada persamaan (13), jika $\Delta \mathrm{x} \rightarrow 0$ dan $\Delta \mathrm{y} \rightarrow 0$ maka truncation term $\rightarrow 0$, sehingga dapat dibuktikan bahwa skema beda hingga eksplisit konsisten terhadap model modifikasi persamaan adveksi-difusi.

\subsection{Menentukan $\Delta \mathbf{x}$ dan $\Delta \mathbf{y}$}

Daerah observasi yang ditentukan pada bab sebelumnya yaitu sesi 3.3 , berukuran $5340 \mathrm{~m} \times 5310 \mathrm{~m}$. Agar skema stabil $\left(\alpha \leq \frac{1}{2}\right)$, dipilih $\Delta \mathrm{y}$ dan $\Delta \mathrm{x}$ berturut-turut $60 \mathrm{~m}$ dan $30 \mathrm{~m}$. Sehingga banyaknya pias pada masing-masing jarak yaitu 89 pias untuk y dan 177 pias untuk $x$.

\subsection{Nilai Awal dan Syarat Batas}

Nilai awal yang digunakan pada penelitian ini yaitu nilai konsentrasi sepanjang garis y $(\mathrm{C}(\mathrm{y}, 30))$. Fungsi konsentrasi merkuri di sepanjang garis y diperoleh melalui interpolasi titiktitik data yang diketahui melewati garis tersebut. Fungsi polinomial hasil interpolasi data di sepanjang garis y $(\mathrm{C}(\mathrm{y}, 30))$, dirumuskan sebagai berikut.

$\mathrm{C}(\mathrm{y}, 30)=0,1010 \mathrm{y}+242,89 ; \mathrm{x}=30 ; 60 \leq \mathrm{y} \leq 2160$

$C(y, 30)=-8,9977 \times 10^{-11} y^{4}+1,1225 \times 10^{-6} y^{3}-0,0050262 y^{2}$

$+9,5409 y-6048,3 ; x=30 ; 60 \leq y \leq 5400$

Berdasarkan asumsi bahwa Sumbu vertikal domain penelitian sejajar dengan arah angin, maka syarat batas pada penelitian ini dibagi menjadi syarat batas kiri dan syarat batas kanan domain penelitian. Syarat batas kiri di sepanjang sumbu- $x$ terhadap $y=60$ meter $(C(60, x))$ dan syarat batas kanan di sepanjang sumbu- $x^{\prime}$ yang sejajar dengan sumbu- $x$ terhadap $y=5400$ meter masing-masing didekati melalui interpolasi fungsi linear seperti di bawah ini :

Syarat batas kiri : $C(60, x)=-0,040301 x+250,21 ; y=60 ; 30 \leq x \leq 5340$

Syarat batas kanan : $C(5400, x)=-0,040301 x+148,3896 ; y=5400 ; 30 \leq x \leq 5340$ (17)

\subsection{Simulasi Pola Penyebaran Uap Mekuri Berdasarkan Karakteristik Stabilitas Atmosfir}

Klasifikasi stabilitas atmosfer dibagi menjadi enam kelas yang diberi label A sampai dengan F, seperti pada tabel berikut: 
Tabel 1 : Klasifikasi Stabilitas Atmosfer

\begin{tabular}{|c|c|c|c|c|c|}
\hline \multirow{2}{*}{ Kecepatan Angin (m/s) } & \multicolumn{3}{|c|}{ Siang Hari } & \multicolumn{2}{c|}{$\begin{array}{c}\text { Malam Hari Tertutup } \\
\text { Awan }\end{array}$} \\
\cline { 2 - 6 } & Tinggi & Sedang & Rendah & $\begin{array}{c}\text { Awan } \\
(\geq 4 / 8)\end{array}$ & $\begin{array}{c}\text { Terang } \\
(\leq 3 / 8)\end{array}$ \\
\hline$<2$ & A & A-B & B & E & F \\
$2-3$ & A-B & B & C & E & F \\
$3-5$ & B & B-C & C & D & E \\
$5-6$ & C & C-D & D & D & D \\
$>6$ & C & D & D & D & D \\
\hline
\end{tabular}

Sumber : (Witono, 2003)

Keterangan :
A : Sangat tidak stabil
E : Sedikit Stabil
B : Cukup tidak stabil
F : Stabil
C : Sedikit tidak stabil
D : Netral diasumsikan cuaca mendung pada malam hari atau siang hari

Simulasi dilakukan untuk data pengukuran merkuri dari penelitian BaliFokus (Indonesia) pada bulan juni tahun 2011. Ukuran daerah sebaran uap merkuri dibagi dalam grid-grid yang sesuai dengan $\Delta \mathrm{y}$ dan $\Delta \mathrm{x}$ yaitu 60 meter dan 30 meter. Parameter dispersi divariasikan untuk setiap stabilitas atmosfer yang bersesuaian. Dispersi penyebaran merkuri bergerak mengikuti arah angin $\mathrm{x}$. Hasil simulasi penyebaran uap merkuri pada kawasan pertambangan emas Poboya dengan stabilitas atmosfer yang berbeda seperti pada Tabel 1 ditunjukkan sebagai berikut.

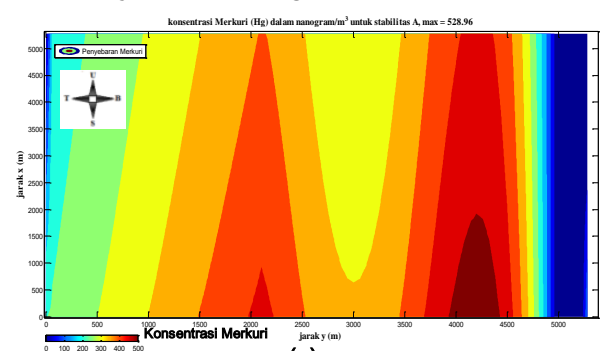

(a)

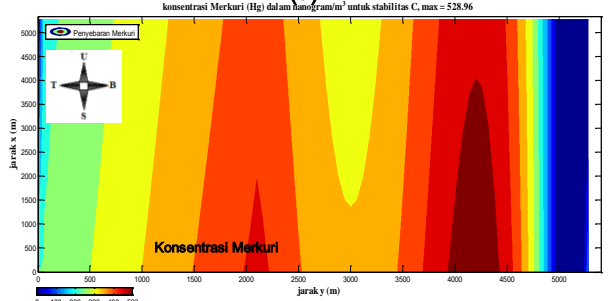

(c)

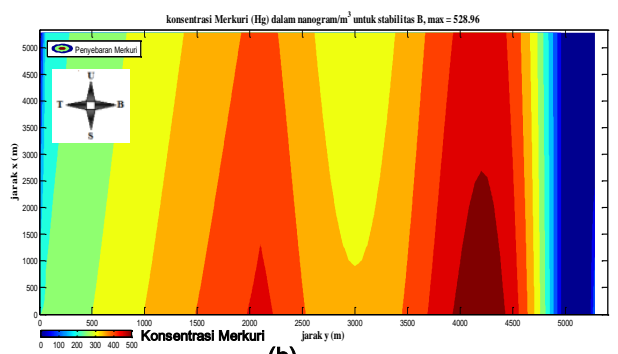

(b)

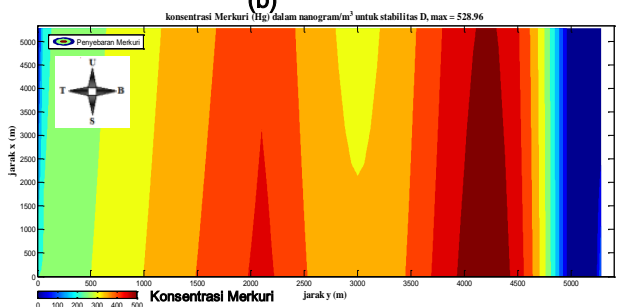

(d) 


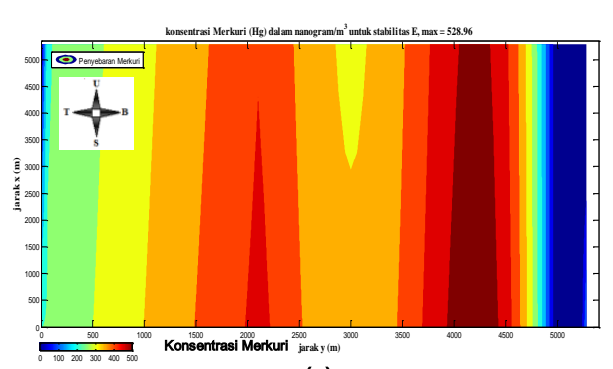

(e)

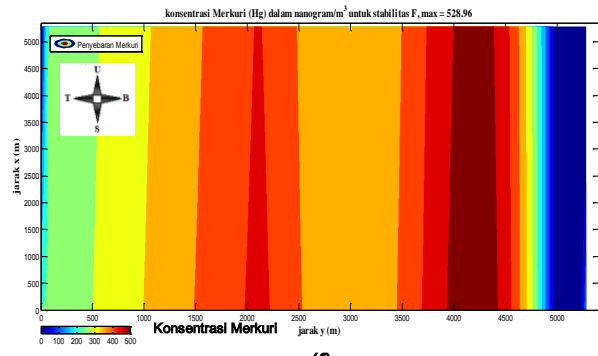

(f)

Gambar 1 : Pola Penyebaran Uap Merkuri (Hg) pada Bulan Juni Tahun 2011 berdasarkan (a) stabilitas atmosfer A, (b) stabilitas atmosfer B, (c) stabilitas atmosfer C, (d) stabilitas atmosfer D, (e) stabilitas atmosfer E, (f) stabilitas atmosfer $\mathrm{F}$

\subsection{Analisis Pola Penyebaran}

Analisa dilakukan terhadap 6 kondisi stabilitas atmosfir yang berbeda. Hasil analisa tersebut adalah sebagai berikut:

a. Makin tingginya kecepatan angin, uap yang keluar dari proses amalgamasi emas akan semakin cepat terdifusi dan teruraikan menyebar ke udara. Sebaliknya, makin lambat kecepatan angin, maka semakin lama uap akan terdifusi dan teruraikan menyebar di udara. Dari hasil simulasi pola penyebaran merkuri cenderung tidak mengalami perubahan kecepatan difusi ke udara karena asumsi bahwa kecepatan angin sama.

b. Keadaan atmosfer labil ditunjukkan pada Gambar 1a hingga 1c. Pada keadaan ini uap merkuri lebih mudah terdifusi dan menyebar ke udara. Sebaliknya, pada keadaan netral (Gambar 1d) hingga keadaan stabil (Gambar 1e dan 1f) uap merkuri cenderung sulit terdifusi dan menyebar ke udara, sehingga jarak jangkauan penyebaran lebih luas dan sangat berbahaya bagi daerah yang berada di lintasan tersebut.

c. Pola penyebaran yang dihasilkan dari Gambar 1a hingga if adalah serupa yakni menuju ke arah angin (x). Gradiasi warna menunjukkan penyebaran merkuri dari konsentrasi tinggi (warna merah tua) menyebar secara perlahan dan berkurang hingga konsentrasi bernilai nol (warna biru tua) pada batas domain penelitian. Hal ini merepresentasikan wilayah dampak penyebaran merkuri di wilayah kota Palu. Wilayah yang paling rentan terkena dampak penyebaran adalah wilayah yang berada di Kelurahan Poboya hingga kecamatan Palu Utara. Hal ini dibuktikan dengan gradiasi warna merah tua pada setiap pola yang dihasilkan terletak mulai dari nilai awal yaitu kawasan Poboya hingga mengarah ke utara yaitu wilayah Palu Utara. Adapun wilayah dampak penyebaran merkuri yang lebih kecil terkena dampak pencemaran merkuri 
adalah wilayah kecamatan Palu Barat. Wilayah ini berada di luar batas kiri domain penelitian. Nilai konsentrasi pada domain batas penelitian menuju ke nol sehingga nilai konsentrasi di luar batas domain penelitian dianggap telah nol pula.

\section{KESIMPULAN}

Dari hasil simulasi model modifikasi persamaan adveksi-difusi menggunakan metode beda hingga diperoleh pola penyebaran merkuri yang sama yakni mengikuti arah angin $(\mathrm{x})$ seperti disimulasikan pada Gambar 1 (a) sampai (f). Berdasarkan kriteria kestabilan atmosfer maka dapat disimpulkan bahwa semakin labil keadaan atmosfer maka semakin cepat terdifusi uap merkuri ke udara. Sebaliknya semakin stabil keadaan atmosfer maka semakin lambat uap merkuri terdifusi dan semakin luas jangkauan daerah penyebarannya. Wilayah dampak pencemaran merkuri di udara pada kawasan pertambangan emas Poboya, kota Palu yang berpotensi sangat besar yaitu Kelurahan Poboya hingga kecamatan Palu Utara, sedangkan yang paling kecil resiko terkena dampak pencemaran merkuri di udara yaitu wilayah Palu Barat.

\section{DAFTAR PUSTAKA}

[1]. Colls, Jeremy., (2002). Air Pollution, Second Edition.Spon Press Taylor dan Francis Group. London.

[2]. http://id.wikipedia.org/wiki/Keadaan_tunak. Diakses 24 Desember 2014.

[3]. Ismawati, Y. (2013). Titik Rawan Merkuri di Indonesia, Situs PESK: Poboya dan Sekotong di Indonesia, Laporan Kampanye Bebas Merkuri IPEN. Balifokus. Denpasar.

[4]. Mosey, H. (2011). Pemodelan Penyebaran Polutan di Udara dengan Solusi Persamaan Difusi Advektif. Jurnal IImiah Sains Vol. 11 No. 1, April 2011. Universitas Samratulangi. Manado.

[5]. Prasetya, P.R.S. (2012). Buku Ajar Persamaan Differensial Parsial. Institut Teknologi Bandung. Bandung.

[6]. Witono, D. (2003). Karakteristik Pencemaran Udara di PLTGU UJB-I Tambak Lorok Semarang. Universitas Diponegoro. Semarang. 